\title{
Concurrent comparison of energy intake and expenditure among adults in Butajira District, Ethiopia
}

\author{
Fikru Tesfaye ${ }^{1, *}$, Peter Byass ${ }^{2}$ and Stig Wall ${ }^{2}$ \\ 'Department of Community Health, Faculty of Medicine, Addis Ababa University, PO Box 11490, Addis Ababa, \\ Ethiopia: ${ }^{2}$ Umeå International School of Public Health, Epidemiology and Public Health Sciences, Department of \\ Public Health and Clinical Medicine, Umeå University, Umeå, Sweden
}

Submitted 7 February 2007: Accepted 27 July 2007: First published online 18 February 2008

\begin{abstract}
Objective: To estimate and compare dietary energy intake (DEI) and total energy expenditure (TEE) among adults, using questionnaires.

Design: Comparative, cross-sectional study.

Setting: Community-based, at the demographic surveillance site (DSS) in Butajira District of Ethiopia.

Subjects: A total of 619 adults, 18-64 years of age, were randomly selected from among the urban and rural population of Butajira using the DSS sampling frame. Habitual dietary intake and physical activity were assessed using questionnaires. BMR was estimated using a regression equation, and TEE was calculated from BMR and the metabolic energy equivalent task (MET) and duration of reported activities. Physical activity level (PAL) was calculated as TEE/BMR, while food intake level (FIL) was calculated as DEI/BMR. The mean DEI:TEE ratio was used to evaluate reported DEI at the population level, while individual misreporters were identified by applying the Goldberg cut-off points at three levels of PAL. Results: Based on the Goldberg method, $57 \%$ of the study participants were identified as acceptable reporters of DEI, among whom mean TEE was 8.21 (95\% CI 8.01, 8.42) MJ (1963 (95\% CI 1914, 2012) kcal), mean DEI was 8.13 (95\% CI $7 \cdot 93,8 \cdot 34)$ MJ (1944 (95\% CI 1895, 1993) kcal) and mean DEI:TEE was $1 \cdot 01$ (95\% CI 0.99, 1.04).

Conclusion: The dietary history and physical activity questionnaires provide comparable estimates of mean energy intake and expenditure at a population level. Acceptable reporters have to be identified in order to obtain better estimates. Questionnaire-based estimates of energy intake should not be interpreted without an inherent system of comparison or validation.
\end{abstract}



Keywords exgy intake Buty level Butajira
Poor diet and physical inactivity are widely prevalent risk factors of chronic diseases such as CVD and diabetes ${ }^{(1)}$. However, accurate and reliable measurement of dietary intake and physical activity at the population level is challenging, particularly in developing countries ${ }^{(2,3)}$.

Various techniques, employing questionnaires, records or objective measurements, have been applied for the assessment of dietary intake and physical activity. However, only a few, such as the doubly labelled water (DLW) method $^{(4)}$, have proved sufficiently precise and unbiased for the estimation of energy expenditure and for the validation of dietary energy intake (DEI) ${ }^{(5,6)}$. Although the DLW method provides an accurate estimation of the mean DEI and physical activity level (PAL), its use in large epidemiological surveys is limited owing to scarcity of the stable isotope and its inhibitory $\operatorname{cost}^{(7)}$.

Dietary intake is reported inaccurately, most often under-reported $^{(8)}$. The DLW method has been used to measure energy expenditure and validate energy intake calculated from food records, diet recalls or diet histories in several studies ${ }^{(9-12)}$, thereby revealing a substantial bias towards underestimation of reported energy intake. Under-reporting of energy expenditure is said to be less common than that of $\mathrm{DEI}^{(13,14)}$, and misreporters of energy intake do not share the same characteristics as misreporters of energy expenditure ${ }^{(14)}$. Thus, estimates of PAL, obtained through a physical activity questionnaire, may be used to evaluate the validity of reported energy intake in the same subject and to identify subjects with a tendency to under-report energy intake ${ }^{(13)}$. On the other hand, some studies have indicated that self-reported instruments have a tendency towards over-reporting of physical activity ${ }^{(2,15)}$ owing to the influence of social desirability and social approval ${ }^{(16)}$.

Methods of assessing energy intake and expenditure have been widely studied in the developed world ${ }^{(17,18)}$ 
while similar information is scarce in the developing world. There is an apparent need to identify feasible methods that offer an acceptable level of accuracy for estimating DEI and PAL at a population level.

\section{Methods}

The present study was conducted as part of a larger research project for surveillance of risk factors of chronic diseases in Butajira District, Ethiopia. The district is inhabited predominantly by the ethnic group collectively known as the 'Guraghe'. Farming and petty trading are the main means of livelihood in the area. Butajira District hosts the Butajira Rural Health Program (BRHP), which is an ongoing demographic surveillance initiated in $1986^{(19)}$. Adults in the age group 18-64 years were randomly selected from among the urban and rural populations, using the BRHP sampling frame. Pregnant women were excluded from the analysis.

The study employed a cross-sectional communitybased design, where two instruments were concurrently applied on the same study participants and the corresponding estimates of energy intake and expenditure were compared. The test-retest reliability of part of the instruments was also examined on a sub-sample of the study participants.

The survey team, data collectors and supervisors were recruited from local youth who had completed highschool education and spoke one or more of the local dialects in addition to Amharic, the national language in Ethiopia. The team was trained on how to identify eligible study subjects, on basic skills of interviewing and recording data, as well as on proper techniques of anthropometric measurements.

Data were collected through interviews and anthropometric measurements. Questionnaires were prepared to allow the collection of data on 'habitual' food intake and usual pattern of physical activity. Thus, study participants were asked to list all the foods and drinks they consume on a usual day. The type and amount of food consumed, the method of preparation (fried, boiled, etc.) and the ingredients (for assorted foods) were queried and recorded in a questionnaire prepared in a table format. The size of household utensils commonly used for serving meals was described by respondents as small, medium or large.

During training of the survey team visits were made to households of volunteer team members, who were also local residents, to observe the common domestic utensils and foods. Pictures of these common types of foods and utensils were taken. The weight of usual sizes (full, half, quarter, etc.) of commonly consumed foods was measured on a few samples. The volume of some household utensils, such as cups, bowls and spoons of common sizes, was also measured. Pictures taken during the visit were used in the training of the survey team.
Participants were asked to list, consecutively, all the activities they undertake in a usual day. The type of activities and the corresponding durations were queried and recorded on the questionnaire. The duration of sleep could be estimated from the usual time they go to bed and get up from bed.

Weight was measured using an ordinary bathroom scale and recorded to the nearest $0.5 \mathrm{~kg}$. Height was measured using a locally produced wooden measuring board and recorded to the nearest $1 \mathrm{~cm}$. Subjects wore minimal (light) clothing and removed their shoes or hats during the measurement. The interview and measurement techniques were standardised through training and pre-testing in the field. The clarity of the questions and their cultural acceptability in the study population were assessed during the pre-test of survey instruments.

Individuals were enrolled into the study on the basis of their informed consent. Ethical conduct was maintained throughout the process of the study.

BMR was estimated separately for males and females across different age groups using the Schofield equation $^{(20)}$. Reported food intake was converted into DEI using the Ethiopian food composition tables ${ }^{(21)}$. The type of food, its main ingredients and the quantity (as estimated from the weight or volume) were used in the process of estimating energy intake.

Total energy expenditure (TEE) of individuals was estimated from the type and duration of reported activities and their respective BMR. MET (metabolic energy equivalent task) factors were assigned to each type of activity and multiplied by the duration to produce energy expenditure due to each type of activity ${ }^{(22,23)}$. A MET factor of 1 was assigned for sleep. TEE was calculated as the sum of all MET due to activity or sleep, during a period of $24 \mathrm{~h}$, multiplied by the BMR of the individual.

PAL was calculated as the ratio of TEE to the estimated BMR (i.e. PAL = TEE/BMR) and food intake level (FIL) was determined as the ratio of DEI to estimated BMR (i.e. $\mathrm{FIL}=\mathrm{DEI} / \mathrm{BMR}$ ). The reported dietary intake was evaluated at the group level by comparing the mean DEI against the mean TEE, and at the individual level by determining the cut-off limits for a plausible energy intake (FIL) as described by Goldberg et al. ${ }^{(24)}$. The Goldberg method was used to calculate the $95 \%$ confidence limits (CL) of FIL assuming a given PAL requirement, below and above which it is unlikely that the mean intake represents either habitual intake for weight maintenance or a random low intake.

Study participants were categorised into low, medium and high activity levels using their estimated PAL and the classification of the FAO/WHO/United Nations University (UNU) Expert Consultation ${ }^{(25)}$, so that different PAL cutoff values would be applied at each level. The Goldberg cut-off values for the $95 \%$ CI of the agreement between FIL and PAL were determined, and the individual FIL was then compared with the respective group PAL cut-off. 
Under-reporters were defined as individuals with FIL values below the lower PAL cut-off for the $95 \% \mathrm{CI}$ of the agreement between FIL and PAL. Acceptable reporters were those with FIL values ranging between the lower and upper limits of the $95 \%$ CI for PAL in the respective group. Those with FIL greater than the upper limit of the $95 \%$ CI of PAL were classified as over-reporters ${ }^{(24,26)}$.

The following formula ${ }^{(24,27)}$ was applied:

$$
\mathrm{EI}: \mathrm{BMR}>\mathrm{PAL} \times \exp [\mathrm{SD} \times(S / 100) / \sqrt{n}],
$$

where PAL is the mean PAL of a group at a given activity level, SD is the number of standard deviations corresponding to the CI chosen ( -2 for the lower CL and +2 for the upper $\mathrm{CL}$ ), $S$ is the overall $\mathrm{CV}$ for PAL, taking into account the variability in energy intake and BMR, and $n$ is the number of individuals included.

$S$ is given by the equation:

$$
S=\sqrt{\left(\mathrm{CV}_{\mathrm{WEI}}^{2} / d\right)+\mathrm{CV}_{\mathrm{WB}}^{2}+\mathrm{CV}_{\mathrm{tP}}^{2}}
$$

where $\mathrm{CV}_{\text {WEI }}^{2}$ is the within-subject variation in energy intake, $d$ is the number of days of diet assessment, $\mathrm{CV}_{\mathrm{WB}}^{2}$ is the within-subject variation in repeated BMR measurements or the precision of estimated compared with measured BMR, and $\mathrm{CV}_{\mathrm{tP}}^{2}$ is the between-subject variation in PAL.

The values used for each factor were $\mathrm{CV}_{\mathrm{WEI}}^{2}=$ $23 \%{ }^{(28,29)}, \mathrm{CV}_{\mathrm{WB}}^{2}=8 \cdot 5 \%$ (for estimated $\mathrm{BMR}$ ), $\mathrm{CV}_{\mathrm{tP}}^{2}=$ $15 \%{ }^{(27)}, d=28 \mathrm{~d}$ and $n=1$, in reference to each individual study participant.

In dietary assessment methods that presume to measure 'habitual' intake, such as the dietary history method, on a large sample $(>500)$, it is suggested that the number of days used in the calculation $(d)$ is conventionally taken as 28 , because the CI for the PAL changes little beyond this level ${ }^{(26,30)}$

As the primary purpose of the present study was to examine the validity of the reported DEI and TEE at a population level, the two measurements were compared as recommended by Black $^{(27)}$. For studies intending to assess 'habitual' DEI at a population level with a sample size greater than 100, Black suggests that the mean FIL may be directly compared with the PAL because in larger studies the $95 \% \mathrm{CI}$ is barely different from the PAL chosen for comparison.

Data were analysed using the Statistical Package for the Social Sciences statistical software package version 11 (SPSS Inc., Chicago, IL, USA). Comparison of mean values and proportions were made using Student's $t$ test and the $\chi^{2}$ test, respectively. The Bland-Altman plot ${ }^{(31)}$ was used to plot the difference between DEI and TEE against their average. Although the physical activity questionnaire was used as the reference instrument in the comparison, it was not intended to be a true 'gold standard', and thus the Bland-Altman analysis allowed an alternative comparison between the two methods.

\section{Results}

A total of 619 adults were enrolled into the study from both rural and urban areas of Butajira District. The majority were in the age group 18-44 years, female, married and Moslem. About half of the study participants were unable to read or write. Farmers, merchants/petty traders and housewives constituted the three main types of occupation among the study population (Table 1).

Mean weight and height were slightly, but significantly, higher among males than females $(P<0.05$ and $P<0 \cdot 01$, respectively). However, mean BMI was comparable between the two sexes, $19.67 \mathrm{~kg} / \mathrm{m}^{2}$ in males and $19.57 \mathrm{~kg} / \mathrm{m}^{2}$ in females (Table 2). About $37 \%$ of the study participants had BMI $<18.5 \mathrm{~kg} / \mathrm{m}^{2}$. BMR, estimated using age- and sex-specific equations, was significantly higher $(P<0 \cdot 001)$ in males than in females (Table 2).

Assessment of the test-retest reliability of the dietary history questionnaire at an interval of $7 \mathrm{~d}$, in a sub-sample of the study population, yielded a significant correlation $\left(r^{2}=0.56, P<0.01\right)$ between the two measurements, although the mean DEI was significantly lower $(-0.59 \mathrm{MJ}$ $(-139 \cdot 82 \mathrm{kcal}), t=-2 \cdot 07, P=0.041)$ in the first measurement. The pooled mean within-individual CV in DEI derived from the repeat measurement was $36 \cdot 2 \%$.

The reported mean duration of activities was 11.5 (sD 2.3) $\mathrm{h}$ in men and 8.8 (SD 3.6) $\mathrm{h}$ in women. The mean DEI was significantly higher $(P<0 \cdot 005)$ in males, 7.96 (SD 3.34) MJ (1901.6 (sD 798.9) kcal), than in females, $7 \cdot 20$ (sD 2.71) MJ (1719.9 (sD 647.5) kcal). The mean DEI:TEE

Table 1 Sociodemographic characteristics of the study population

\begin{tabular}{lrr}
\hline & $n$ & $\%$ \\
\hline Residence & & \\
$\quad$ Urban & 304 & $49 \cdot 1$ \\
Rural & 315 & $50 \cdot 9$ \\
Sex & & \\
Male & 244 & $39 \cdot 4$ \\
Female & 375 & $60 \cdot 6$ \\
Age (years) & & \\
18-24 & 179 & $28 \cdot 9$ \\
25-34 & 201 & $32 \cdot 5$ \\
35-44 & 131 & $21 \cdot 2$ \\
45-54 & 60 & $9 \cdot 7$ \\
55-64 & 48 & $7 \cdot 8$ \\
Marital status & & \\
Married & 434 & $70 \cdot 1$ \\
Never married & 148 & $23 \cdot 9$ \\
Divorced/separated/widowed & 37 & $6 \cdot 0$ \\
Literacy status & & \\
Unable to read or write & 321 & $51 \cdot 9$ \\
Able to read and write & 298 & $48 \cdot 1$ \\
Religion & & \\
$\quad$ Moslem & 456 & $73 \cdot 7$ \\
Christian & 163 & $26 \cdot 3$ \\
Occupation & & \\
Farmer & & \\
Merchant or petty trader & 180 & $29 \cdot 1$ \\
Housewife & 154 & $21 \cdot 9$ \\
Student & 130 & $11 \cdot 6$ \\
Other & 72 & $13 \cdot 2$ \\
\hline$\quad$ & 82 & \\
\hline & & \\
\hline & &
\end{tabular}


ratio was similar between men, 0.93 (SD 0.44), and women, 0.94 (SD 0.41). The resulting FIL was not significantly different between males, $1 \cdot 31$ (sD 0.56), and females, 1.39 (SD 0.53 ). On the other hand, while the mean TEE, 8.89 (SD 2.04) MJ (2124.1 (SD 488.1) kcal), was significantly higher among men, the corresponding PAL, 1.54 (sD 0.37), was significantly higher in females, which might

Table 2 Anthropometric characteristics and predicted BMR*

\begin{tabular}{|c|c|c|c|c|c|c|}
\hline & \multicolumn{2}{|c|}{ Males (n 244) } & \multicolumn{2}{|c|}{ Females ( $n$ 375) } & & \multirow[b]{2}{*}{$P$} \\
\hline & Mean & SD & Mean & SD & & \\
\hline Weig & $52 \cdot 4$ & $7 \cdot 2$ & $51 \cdot 1$ & $7 \cdot 5$ & $2 \cdot 16$ & 0.031 \\
\hline Heig & $1 \cdot 63$ & 0.08 & $1 \cdot 60$ & $0 \cdot 15$ & $2 \cdot 64$ & 0.008 \\
\hline $\operatorname{BMI}\left(\mathrm{kg} / \mathrm{m}^{2}\right)$ & $19 \cdot 7$ & $2 \cdot 9$ & $19 \cdot 6$ & $2 \cdot 30$ & 0.48 & 0.63 \\
\hline BMR $(\mathrm{MJ} / \mathrm{d})$ & $6 \cdot 10$ & 0.51 & $5 \cdot 22$ & 0.39 & $23 \cdot 8$ & 0.000 \\
\hline BMR (kcal/d) & 1457 & 123 & 1248 & 94 & $23 \cdot 8$ & 0.000 \\
\hline
\end{tabular}

*BMR was estimated using the Schofield equation ${ }^{(20)}$. be due to the higher BMR in males. The mean (SD) and 95\% CI for the four parameters are indicated in Table 3.

Based on the PAL classification by FAO/WHO/UNU ${ }^{(25)}$, $76.6 \%$ of the study population fell in the sedentary or light activity lifestyle category, with a $\mathrm{PAL}<1 \cdot 7$. The proportion of the population with an active or moderately active lifestyle was $14 \cdot 2 \%$, while the remaining $9 \cdot 2 \%$ of the population were classified as having a vigorous or vigorously active lifestyle. A stratified analysis of PAL classified more women into the vigorously active lifestyle $(25 \cdot 3 \% v \cdot 6 \cdot 1 \%)$ while more men were classified under the sedentary or light activity lifestyle (78.7\% v. 64.5\%). The difference in the distribution of PAL between the two sexes was statistically significant $\left(\chi^{2}=37 \cdot 93, P<0 \cdot 001\right)$.

Mean TEE and DEI, as well as the resulting PAL and FIL, were compared across different population groups. As presented in Table 4, mean TEE and PAL were significantly higher than DEI and FIL, respectively, among the urban population group. On the other hand, among

Table 3 Distribution of DEI, TEE, FIL and PAL by sex in Butajira District, Ethiopia

\begin{tabular}{|c|c|c|c|c|c|c|}
\hline & \multicolumn{3}{|c|}{ Males } & \multicolumn{3}{|c|}{ Females } \\
\hline & Mean & SD & $95 \% \mathrm{Cl}$ & Mean & SD & $95 \% \mathrm{Cl}$ \\
\hline DEI (MJ) & $7 \cdot 95$ & 3.34 & $7 \cdot 54,8 \cdot 38$ & $7 \cdot 20$ & $2 \cdot 71$ & $6 \cdot 92,7 \cdot 47$ \\
\hline DEI (kcal) & 1901 & 799 & 1802, 2002 & 1720 & 648 & 1654,1786 \\
\hline TEE (MJ) & $8 \cdot 89$ & $2 \cdot 04$ & $8 \cdot 63,9 \cdot 14$ & 8.05 & $2 \cdot 15$ & $7 \cdot 84,8 \cdot 27$ \\
\hline TEE (kcal) & 2124 & 488 & 2063,2185 & 1925 & 515 & 1873,1977 \\
\hline DEI:TEE & 0.93 & 0.44 & $0.88,0.98$ & 0.94 & 0.41 & $0.90,0.98$ \\
\hline FIL (=DEI/BMR) & $1 \cdot 31$ & 0.56 & $1 \cdot 24,1 \cdot 38$ & $1 \cdot 39$ & 0.53 & $1 \cdot 34,1 \cdot 44$ \\
\hline PAL (=TEE/BMR) & $1 \cdot 45$ & 0.29 & $1 \cdot 41,1 \cdot 49$ & 1.54 & 0.37 & $1.50,1.58$ \\
\hline
\end{tabular}

DEI, dietary energy intake; TEE, total energy expenditure; FIL, food intake level; PAL, physical activity level.

Table 4 Comparison of (a) mean TEE and DEI, and (b) mean PAL and FIL, across residence and sex in Butajira District, Ethiopia

\begin{tabular}{|c|c|c|c|c|c|c|c|c|c|c|c|}
\hline & \multirow[b]{2}{*}{$n$} & \multicolumn{2}{|c|}{ TEE } & \multicolumn{2}{|c|}{ DEI } & \multicolumn{2}{|c|}{ Mean difference } & \multicolumn{2}{|c|}{$95 \% \mathrm{CL}$ of mean difference } & \multirow[b]{2}{*}{$t$} & \multirow[b]{2}{*}{$P$} \\
\hline & & $(\mathrm{MJ})$ & (kcal) & $(\mathrm{MJ})$ & (kcal) & (MJ) & (kcal) & Lower (MJ/kcal) & Upper (MJ/kcal) & & \\
\hline \multicolumn{12}{|c|}{ (a) Mean TEE and DEI } \\
\hline \multicolumn{12}{|c|}{ Urban } \\
\hline Both sexes & 304 & $8 \cdot 44$ & $2016 \cdot 8$ & $6 \cdot 55$ & $1566 \cdot 0$ & $1 \cdot 89$ & $450 \cdot 7$ & $1 \cdot 41 / 336 \cdot 3$ & $2 \cdot 25 / 538 \cdot 1$ & $10 \cdot 15$ & 0.000 \\
\hline Males & 110 & $8 \cdot 86$ & $2118 \cdot 7$ & $6 \cdot 87$ & $1642 \cdot 9$ & 1.99 & $475 \cdot 8$ & $1 \cdot 36 / 324 \cdot 3$ & $2 \cdot 62 / 627 \cdot 2$ & $6 \cdot 22$ & 0.000 \\
\hline Females & 194 & $8 \cdot 20$ & $1959 \cdot 0$ & $6 \cdot 37$ & $1522 \cdot 5$ & $1 \cdot 83$ & $436 \cdot 5$ & $1 \cdot 38 / 328 \cdot 9$ & $2 \cdot 28 / 544 \cdot 2$ & 8.00 & 0.000 \\
\hline \multicolumn{12}{|l|}{ Rural } \\
\hline Both sexes & 315 & $8 \cdot 33$ & $1990 \cdot 7$ & $8 \cdot 41$ & $2009 \cdot 1$ & -0.08 & $-18 \cdot 4$ & $-0.46 /-110 \cdot 1$ & $0.31 / 73 \cdot 3$ & -0.39 & 0.693 \\
\hline Males & 134 & $8 \cdot 91$ & $2128 \cdot 5$ & $8 \cdot 84$ & $2113 \cdot 9$ & 0.06 & $14 \cdot 5$ & $-0 \cdot 61 /-145 \cdot 1$ & $0 \cdot 73 / 174 \cdot 1$ & $0 \cdot 18$ & 0.858 \\
\hline \multirow[t]{3}{*}{ Females } & 181 & $7 \cdot 90$ & $1888 \cdot 7$ & $8 \cdot 08$ & $1931 \cdot 6$ & $-0 \cdot 18$ & $-42 \cdot 8$ & $-0 \cdot 63 /-151 \cdot 4$ & $0 \cdot 27 / 65 \cdot 7$ & $-0 \cdot 77$ & 0.438 \\
\hline & & & & & & & & \multicolumn{2}{|c|}{$95 \% \mathrm{CL}$ of mean difference } & & \\
\hline & $n$ & \multicolumn{2}{|c|}{ PAL } & \multicolumn{2}{|c|}{ FIL } & \multicolumn{2}{|c|}{ Mean difference } & Lower & Upper & $t$ & $P$ \\
\hline \multirow{2}{*}{\multicolumn{12}{|c|}{$\begin{array}{l}\text { (b) Mean PAL and FIL } \\
\text { Urban }\end{array}$}} \\
\hline & & & & & & & & & & & \\
\hline Both sexes & 304 & \multirow{2}{*}{\multicolumn{2}{|c|}{$\begin{array}{l}1 \cdot 50 \\
1.42\end{array}$}} & \multicolumn{2}{|c|}{$1 \cdot 18$} & \multicolumn{2}{|c|}{$0 \cdot 32$} & 0.25 & $0 \cdot 38$ & $10 \cdot 15$ & 0.000 \\
\hline Males & 110 & & & \multirow{2}{*}{\multicolumn{2}{|c|}{$\begin{array}{l}1 \cdot 12 \\
1 \cdot 21\end{array}$}} & \multirow{2}{*}{\multicolumn{2}{|c|}{$0 \cdot 30$}} & 0.20 & 0.40 & $6 \cdot 00$ & 0.000 \\
\hline Females & 194 & \multicolumn{2}{|c|}{1.55} & & & & & 0.24 & 0.41 & $7 \cdot 70$ & 0.000 \\
\hline \multicolumn{12}{|l|}{ Rural } \\
\hline Both sexes & 315 & \multicolumn{2}{|c|}{$1 \cdot 50$} & \multicolumn{2}{|c|}{$1 \cdot 52$} & \multicolumn{2}{|c|}{-0.02} & -0.09 & 0.04 & -0.73 & 0.461 \\
\hline Males & 134 & \multicolumn{2}{|c|}{$1 \cdot 47$} & \multicolumn{2}{|c|}{$1 \cdot 47$} & \multicolumn{2}{|c|}{0.00} & $-0 \cdot 10$ & $0 \cdot 11$ & 0.05 & 0.953 \\
\hline Females & 181 & \multicolumn{2}{|c|}{1.51} & \multicolumn{2}{|c|}{$1 \cdot 56$} & -0 & & 0.04 & $-0 \cdot 13$ & $-1 \cdot 06$ & 0.289 \\
\hline
\end{tabular}

TEE, total energy expenditure; DEl, dietary energy intake; PAL, physical activity level; FIL, food intake level; CL, confidence limit. 
the rural population, the mean differences between TEE and DEI, as well as between PAL and FIL, were not significantly different from zero.

We also evaluated the reported DEI or FIL at an individual level so as to identify acceptable reporters and differentiate their characteristics from those of possible under-reporters and over-reporters. The findings revealed that $32.3 \%$ of the study participants were under-reporters, while $57 \cdot 0 \%$ were acceptable reporters and the remaining $10 \cdot 7 \%$ were over-reporters.

Table 5 indicates the PAL values used to classify study participants into low, medium and high activity levels, the mean PAL of each group, and the lower and upper Goldberg cut-off points calculated for each PAL value.

The consistency between the group- and individuallevel evaluation, i.e. assessment of the overall bias in reporting DEI at the group level and identifying individual under-reporters, was explored by comparing the mean TEE, DEI, PAL and FIL across under-reporters, acceptable reporters and over-reporters. This revealed that, among the three groups, the most comparable esti-

Table 5 Goldberg cut-off points and $95 \% \mathrm{CL}$ of FIL, which differentiate acceptable reporters from under-reporters and overreporters

\begin{tabular}{lccc}
\hline & & \multicolumn{2}{c}{$95 \%$ CL+ } \\
\cline { 3 - 4 } PAL classification $^{*}$ & Mean PAL & Lower & Upper \\
\hline Males & & & \\
$\quad \leq 1.70$ & 1.35 & 0.95 & 1.93 \\
$1 \cdot 71-1.99$ & 1.83 & 1.28 & 2.61 \\
$\quad \geq 2 \cdot 0$ & $2 \cdot 11$ & 1.48 & 3.01 \\
Females & & & \\
$\leq 1.70$ & 1.36 & 0.95 & 1.94 \\
$1.71-1.99$ & 1.83 & 1.28 & 2.61 \\
$\geq 2.0$ & 2.29 & 1.60 & 3.27
\end{tabular}

$\mathrm{CL}$, confidence limit; FIL, food intake level; PAL, physical activity level. ${ }^{*} \mathrm{PAL}$ classification modified from FAO/WHO/United Nations University, $2004^{(25)}$.

$+95 \% \mathrm{CL}$ calculated using the following assumptions: $\mathrm{CV}_{\mathrm{WEI}}^{2}=23 \%$, $\mathrm{CV}_{\mathrm{WB}}^{2}=8.5 \%, \mathrm{CV}_{\mathrm{tP}}^{2}=15 \%$, and assuming $28 \mathrm{~d}$ for the dietary history method. mates between TEE and DEI, or PAL and FIL, were obtained among acceptable reporters, where the mean differences between the parameters were not significantly different from zero. Acceptable reporters had a mean TEE of $8 \cdot 21(95 \%$ CI 8·01, 8•42) MJ (1963 (95\% CI 1914, 2012) $\mathrm{kcal})$ and mean DEI of $8 \cdot 13$ (95\% CI 7·93, 8.34) MJ (1944 (95\% CI 1895, 1993) kcal) (Table 6).

Acceptable reporters also had the most desired ratio (closest to 1) between mean DEI and TEE, 1.01 (95\% CI $0.99,1.04)$, unlike under-reporters $(0.53)$ or overreporters (1.74). Classification of the study subjects according to their reporting status improved the correlation between DEI and TEE, from $r=0 \cdot 108$ before the classification to $r=0.543$ among under-reporters, $r=0.531$ among acceptable reporters and $r=0.469$ among over-reporters. All of the correlations were significant at $P<0 \cdot 01$.

Figure 1 presents the Bland-Altman plot of the difference between DEI and TEE against the average between DEI and TEE, separately for urban and rural study participants. It is evident from the figure that acceptable reporters are symmetrically distributed (concentrated) along the line representing zero difference between DEI and TEE, and around the average DEI + TEE of $8.37 \mathrm{MJ}(2000 \mathrm{kcal})$. However, under-reporters and over-reporters are asymmetrically distributed below and above the acceptable reporters, respectively.

Under-reporters were more common among the urban sample, and at low average DEI + TEE values, while overreporters were more common in the rural sample and at higher average DEI + TEE levels. The plot identified under-reporters at all levels of average energy intake, while over-reporters were mainly concentrated at high energy intake levels.

The observed high level of under-reporting among urban population groups prompted further comparison between the two populations. Thus significant differences $(P<0 \cdot 001)$ were also detected in mean DEI and the corresponding FIL between the two groups. The mean

Table 6 Comparison of (a) mean TEE and DEI, and (b) mean PAL and FIL, among under-reporters and non under-reporters in Butajira District, Ethiopia

\begin{tabular}{|c|c|c|c|c|c|c|c|c|c|c|c|}
\hline & \multirow[b]{2}{*}{$n$} & \multicolumn{2}{|c|}{ TEE } & \multicolumn{2}{|c|}{$\mathrm{DEI}$} & \multicolumn{2}{|c|}{ Mean difference } & \multicolumn{2}{|c|}{$95 \% \mathrm{Cl}$ of mean difference } & \multirow[b]{2}{*}{$t$} & \multirow[b]{2}{*}{$P$} \\
\hline & & $(\mathrm{MJ})$ & (kcal) & (MJ) & (kcal) & (MJ) & (kcal) & $(\mathrm{MJ})$ & (kcal) & & \\
\hline \multicolumn{12}{|l|}{ (a) Mean TEE and DEI } \\
\hline Under-reporters & 200 & $9 \cdot 05$ & $2161 \cdot 8$ & $4 \cdot 72$ & $1127 \cdot 1$ & $4 \cdot 33$ & $1034 \cdot 6$ & $4 \cdot 04,4 \cdot 62$ & $965 \cdot 1,1104 \cdot 1$ & $29 \cdot 35$ & 0.000 \\
\hline Acceptable reporters & 353 & $8 \cdot 21$ & $1962 \cdot 5$ & $8 \cdot 13$ & $1944 \cdot 0$ & 0.08 & $18 \cdot 08$ & $-0.12,0.28$ & $-28 \cdot 8,65 \cdot 8$ & 0.77 & 0.442 \\
\hline \multirow[t]{2}{*}{ Over-reporters } & 66 & $7 \cdot 29$ & $1743 \cdot 2$ & $12 \cdot 51$ & $2989 \cdot 3$ & $-5 \cdot 21$ & $-1246 \cdot 1$ & $-5 \cdot 79,-4 \cdot 64$ & $-1383 \cdot 8,-1108 \cdot 4$ & $-18 \cdot 076$ & 0.000 \\
\hline & $n$ & \multicolumn{2}{|c|}{ PAL } & \multicolumn{2}{|c|}{ FIL } & \multicolumn{2}{|c|}{ Mean difference } & \multicolumn{2}{|c|}{$95 \% \mathrm{Cl}$ of mean difference } & $t$ & $P$ \\
\hline \multicolumn{12}{|l|}{ (b) Mean PAL and FIL } \\
\hline Under-reporters & 200 & \multicolumn{2}{|c|}{$1 \cdot 58$} & \multicolumn{2}{|c|}{0.82} & \multicolumn{2}{|c|}{0.754} & \multicolumn{2}{|c|}{$0 \cdot 70,0 \cdot 80$} & $29 \cdot 97$ & 0.000 \\
\hline Acceptable reporters & 353 & \multirow{2}{*}{\multicolumn{2}{|c|}{$\begin{array}{l}1.48 \\
1.37\end{array}$}} & \multirow{2}{*}{\multicolumn{2}{|c|}{$\begin{array}{l}1 \cdot 47 \\
2 \cdot 35\end{array}$}} & \multirow{2}{*}{\multicolumn{2}{|c|}{$\begin{array}{r}0.011 \\
-0.974\end{array}$}} & \multicolumn{2}{|c|}{$-0.02,0.04$} & 0.629 & 0.530 \\
\hline Over-reporters & 66 & & & & & & & \multicolumn{2}{|c|}{$-1.07,-0.87$} & $-19 \cdot 54$ & 0.000 \\
\hline
\end{tabular}

TEE, total energy expenditure; DEI, dietary energy intake; PAL, physical activity level; FIL, food intake level. 

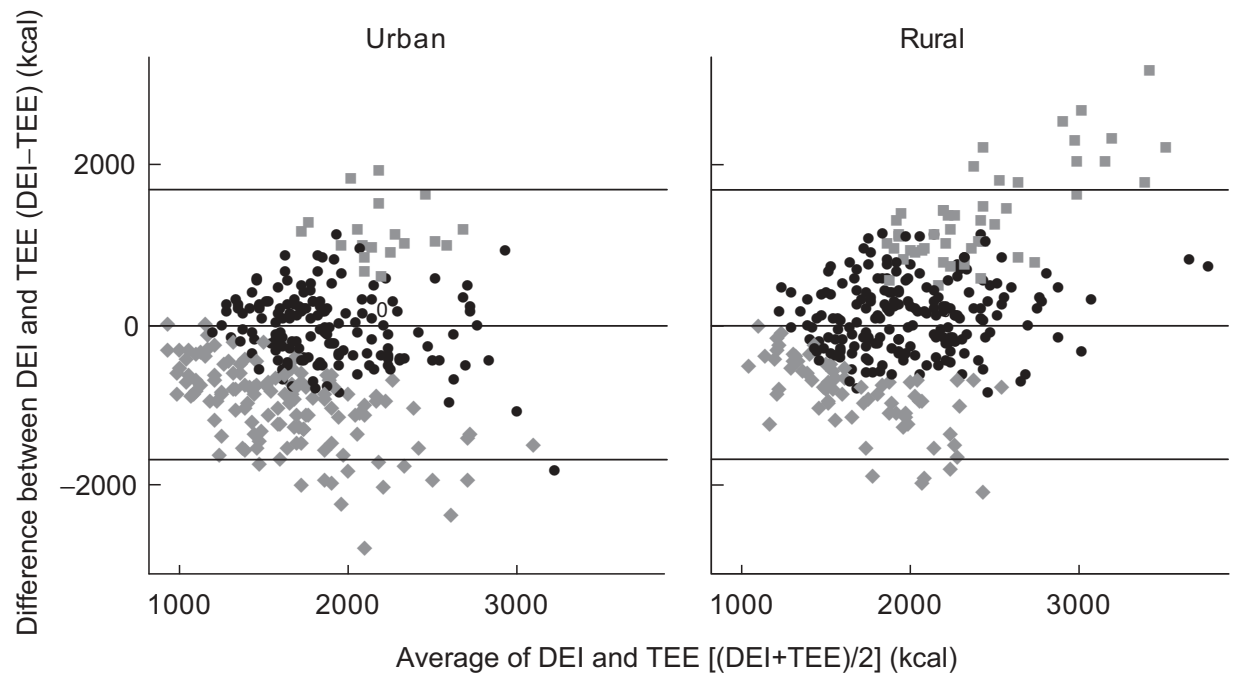

Fig. 1 Bland-Altman plot of the difference between dietary energy intake (DEI) and total energy expenditure (TEE) against the average of DEI and TEE for acceptable reporters $(\bullet)$, over-reporters $(\bullet)$ and under-reporters $(\diamond)$. Horizontal lines represent the mean ( $\pm 2 \mathrm{SD}$ ) for the difference between DEI and TEE. To convert from kcal to MJ, multiply by $4 \cdot 184$ and divide by 1000

Table 7 Comparison of DEI, TEE, FIL and PAL by residence in Butajira District, Ethiopia

\begin{tabular}{|c|c|c|c|c|c|c|}
\hline & \multicolumn{2}{|c|}{ Urban } & \multicolumn{2}{|c|}{ Rural } & \multirow[b]{2}{*}{$t$} & \multirow[b]{2}{*}{$P$} \\
\hline & Mean & SD & Mean & SD & & \\
\hline DEI (MJ) & $6 \cdot 55$ & $2 \cdot 53$ & $8 \cdot 41$ & $3 \cdot 13$ & -8.09 & 0.000 \\
\hline DEI (kcal) & $1566 \cdot 0$ & $605 \cdot 6$ & $2009 \cdot 2$ & $747 \cdot 1$ & -8.09 & 0.000 \\
\hline TEE (MJ) & 8.44 & $2 \cdot 34$ & $8 \cdot 33$ & 1.95 & 0.63 & 0.53 \\
\hline TEE (kcal) & $2016 \cdot 8$ & $558 \cdot 2$ & $1990 \cdot 7$ & $466 \cdot 6$ & 0.63 & 0.53 \\
\hline FIL & $1 \cdot 18$ & 0.47 & 1.53 & 0.56 & $-8 \cdot 21$ & 0.000 \\
\hline PAL & 1.51 & 0.38 & $1 \cdot 50$ & 0.31 & 0.23 & 0.82 \\
\hline DEI:TEE & 0.82 & 0.38 & 1.05 & 0.43 & -6.93 & 0.000 \\
\hline
\end{tabular}

DEI, dietary energy intake; TEE, total energy expenditure; FIL, food intake level; PAL, physical activity level.

DEI in urban areas of Butajira District was 6.55 (95\% CI $6 \cdot 27,6 \cdot 84)$ MJ (1566 (95\% CI 1498, 1634) kcal), while in the rural areas it was $8 \cdot 41$ (95\% CI 8•06, 8.75) MJ (2009 $(95 \%$ CI 1926, 2091) kcal), whereas TEE and PAL were not significantly different between the two groups $(P>0 \cdot 05)$. The mean DEI:TEE ratio was also significantly lower ( $t=-6.93, \quad P<0.001$ ) among urban residents, 0.82 $(\mathrm{SD} 0 \cdot 38)$, than in rural ones, $1 \cdot 05(\mathrm{SD} 0 \cdot 43)$ (Table 7$)$.

\section{Discussion}

We compared energy intake and expenditure from selfreported questionnaires on the basis of the principle of energy balance ${ }^{(24,27)}$. Under conditions of energy balance energy intake equals energy expenditure, and the measurement of energy expenditure may be used to examine the validity of energy intake ${ }^{(25)}$. As with all self-reported measurements, there were obvious concerns with the accuracy of both instruments. Thus, we employed the Goldberg technique ${ }^{(24)}$ to classify the study population into low, medium and high activity levels, in order to identify misreporting and improve the validity of estimates of DEI and TEE from the self-reported questionnaires.

The estimated mean DEI in the present study is closely comparable with earlier reports of per capita daily energy intake from urban $(7 \cdot 27 \mathrm{MJ}(1738 \mathrm{kcal}))$ and rural (9.17 MJ (2191 kcal)) areas of Ethiopia in 2000. A similar report for 1996 indicated $8 \cdot 04 \mathrm{MJ}(1921 \mathrm{kcal})$ for urban and $8 \cdot 13 \mathrm{MJ}(1942 \mathrm{kcal})$ for rural areas. The reported energy intake for urban centres located close to the present study site varied between 6.14 and 7•06 MJ (1467 and $1688 \mathrm{kcal})^{(32)}$. The low DEI in the study population is consistent with the high prevalence of chronic energy deficiency or adult undernutrition (37\%) in the area.

Mean DEI was significantly higher in rural residents and males compared with their urban and female counterparts, respectively. The observed difference may be due largely to under-reporting as evidenced by the low FIL (1·18) in urban areas. The mean DEI:TEE ratio (1.05) speaks to a better accuracy of the DEI report among rural populations compared with the much lower ratio $(0 \cdot 82)$ in urban areas. The difference in mean DEI:TEE ratio 
between the two population groups was statistically significant $(t=-6.93, P<0 \cdot 001)$.

Studies that have compared mean DEI from several methods simultaneously in the same subjects ${ }^{(33,34)}$ give inconsistent results concerning the relative accuracy of the different dietary assessment methods. In some the dietary history method provided more accurate mean estimates of DEI than found in diet records ${ }^{(35)}$, while the reverse has also been observed in others ${ }^{(36)}$.

In a review of eleven studies where reported energy intake was compared with energy expenditure by the DLW method ${ }^{(33)}$, the overall mean DEI:TEE values for men and women respectively were $0 \cdot 87$ (SD 0.09) and $0 \cdot 85$ (sD 0.09). The most accurate DEI:TEE ratios (1.06) were reported from studies where food intake was observed. There was no significant difference across the other methods, such as dietary history, weighed record, estimated record, $24 \mathrm{~h}$ recall or FFQ. The overall mean DEI:TEE estimated by the different studies, as compared with the DLW method, was 0·86. Another summary of DLW studies with measurements of both DEI and TEE found that, in forty-four studies, the mean DEI:TEE ratio was $0 \cdot 84$, and thirty-five out of fifty-six subgroups had a reported mean DEI:TEE below $0 \cdot 90^{(34)}$.

Although we have not used the DLW or any other objective measure of TEE in the present study, use of the dietary history questionnaire against the physical activity questionnaire gave DEI:TEE ratio of very high accuracy (1.05) among the rural study participants. This value, along with the ratios of 0.93 in males and 0.94 in females, substantiates comparability of the questionnaires for measuring mean DEI and TEE at the population level. The mean FIL in our study, 1.31 in males and 1.39 in females, was lower than in most reports. In the analysis of nearly 600 DLW measurements the mean PAL in freeliving people was greater than $1 \cdot 55$. The range of usual PAL for normally active persons was estimated to range from $1 \cdot 3$ to $2 \cdot 0$ in women and $2 \cdot 4$ in men ${ }^{(30)}$.

Application of different PAL cut-off points at three activity levels classified close to $57 \%$ of the study population as acceptable reporters of DEI, while about $36 \%$ were under-reporters. Black ${ }^{(26)}$ affirmed that the use of cut-off values depending on individual level of physical activity provides a better definition of under-reporters. The Goldberg technique is said to have poor sensitivity for defining misreporters at the individual level. Moreover, due to the wide confidence limits, it will only allow identification of extreme degrees of misreporting ${ }^{(27)}$. Thus the present study might have not identified all possible under-reporters of DEI.

The level of under-reporting in the current study population is comparable with other reports. In a review of twenty-two studies with measurements of TEE by the DLW method, the proportion of acceptable reporters was $62 \%$, while $34 \%$ were under-reporters and $4 \%$ were overreporters ${ }^{(26)}$. A few studies conducted in developing countries have reported rates of under-reporting using the FFQ: $22.5 \%$ in men and $38.6 \%$ in women in Jamaica $^{(37)}, 43 \%$ in South Africa ${ }^{(38)}$.

Evaluation of the accuracy of reported DEI aims to attain a DEI:TEE ratio of 1 . Thus population groups with ratios closest to 1 could be regarded as providing valid reports. In the present study, acceptable reporters, identified through the application of PAL cut-offs, provided the most desired DEI:TEE ratio $1 \cdot 01$, which further substantiates agreement between the methods of evaluation applied at the group and individual levels. The improved correlation between reported DEI and TEE following the classification by reporting status provides further evidence for the importance of the Goldberg method.

The Bland-Altman plot ${ }^{(31)}$ was in agreement with the other approaches of comparison employed in the present study, graphically revealing the distinct distribution of acceptable reporters from the under-reporters and overreporters. The plot illustrated that under-reporters were more concentrated at lower average DEI levels while over-reporters were more common at higher levels of DEI. The plot visually reaffirms the ability of the Goldberg technique we employed to differentiate different types of misreporters of DEI.

In the present study mean DEI among acceptable reporters was markedly higher than the overall mean before the classification. This finding, of a higher proportion of under-reporters, signifies that use of a dietary history questionnaire without an in-built validation component could bias the outcome of studies which examine the association between diet and diseases, leading to flawed interpretation.

In addition to systematic misreporting, unacceptably low DEI might result from erroneous estimation of the amount of food consumed, or while converting food intake into nutrient intake. Although Ethiopia is one of the few African countries with a national food composition table, not all food items reported in the study area could be obtained in the same composition in the tables. Errors in the process of data collection might have also contributed to misreporting.

Errors could also be introduced while assigning MET values to a given activity type. The Compendium of Physical Activities ${ }^{(39)}$ was intended primarily for use in epidemiological studies to standardise the assignment of MET intensities in physical activity questionnaires. Individual variations in energy expenditure for the same activity could result in inaccurate assignment of MET values as the compendium does not account for differences in biological, geographic or environmental conditions in which the activities are performed. However, we assume that such errors may not markedly alter the population mean values as they are likely to be distributed randomly.

Neither energy expenditure nor BMR was measured objectively in the present study. Thus, the lack of 
biomarkers, such as the DLW method, is an apparent limitation. On the other hand, the stated limitation was the basis for attempting to produce more practical methods with reasonable accuracy and reliability. Our study design did not allow us to quantify or account for misreporting of physical activity, which might have been under-reported or over-reported. Thus correlated error, which is common feature of concurrent comparison studies, is a possible limitation in our study too.

The questionnaire-based assessment of habitual dietary intake and physical activity offers an inexpensive and practical alternative for estimating DEI and PAL of populations in low-income settings. As energy intake and expenditure are interdependent behaviours, the assessment of dietary intake and physical activity should be linked to one another so as to enable evaluation of the energy balance and cross-examination of the validity of each with the other.

\section{Acknowledgements}

Financial support for this study was made available by the WHO, Geneva, and through a special grant from the Swedish Council for Social and Work Life Research (FAS), No. 2003-0075. The Butajira Rural Health Program and study participants residing at the demographic surveillance site are greatly acknowledged.

\section{References}

1. World Health Organization (2002) World Health Report 2002: Reducing Risks, Promoting Healthy Life. Geneva: WHO

2. Rzewnicki R, Auweele YV \& De Bourdeaudhuij I (2003) Addressing overreporting on the International Physical Activity Questionnaire (IPAQ) telephone survey with a population sample. Public Health Nutr 6, 299-305.

3. Craig CL, Marshall AL, Sjostrom M et al. (2003) International physical activity questionnaire: 12-country reliability and validity. Med Sci Sports Exerc 35, 1381-1395.

4. Coward W (1988) The doubly-labeled-water $\left({ }^{2} \mathrm{H}_{2}{ }^{18} \mathrm{O}\right)$ method: principles and practice. Proc Nutr Soc $\mathbf{4 7}$, 209-218.

5. Seale JL, Rumpler WV, Conway JM \& Miles CW (1990) Comparison of energy expenditure using doubly labeled water, intake balance, and direct/indirect calorimetry methods in adult men. Am J Clin Nutr 52, 66-71.

6. Starling RD, Matthews DE, Ades PA \& Poehlman ET (1999) Assessment of physical activity in older individuals: a doubly labeled water study. J Appl Physiol 86, 2090-2096.

7. Irwin ML, Ainsworth BE \& Conway JM (2001) Estimation of energy expenditure from physical activity measures: determinants of accuracy. Obes Res $\mathbf{9}, 517-525$.

8. Hill R \& Davies P (2001) The validity of self-reported energy intake as determined using the doubly labelled water technique. BrJ Nutr 85, 415-430.

9. Black AE, Prentice AM, Goldberg GR, Jebb SA, Bingham SA, Livingstone MB \& Coward WA (1993) Measurements of total energy expenditure provide insights into the validity of dietary measurements of energy intake. J Am Diet Assoc 93, 572-579.
10. Black AE, Goldberg GR, Jebb SA, Livingstone MB \& Prentice AM (1991) Critical evaluation of energy intake data using fundamental principles of energy physiology: 2 . Evaluating the results of dietary surveys. Eur J Clin Nutr $\mathbf{4 5}$, 583-599.

11. Black AE, Coward WA, Cole TJ \& Prentice AM (1996) Human energy expenditure in affluent societies: analysis of 574 doubly-labeled water measurements. Eur J Clin Nutr 50, 72-92.

12. Black AE, Bingham SA, Johansson G \& Coward WA (1997) Validation of dietary intakes of protein and energy against 24 hour urinary $\mathrm{N}$ and DLW energy expenditure in middle aged women and retired men: comparison with validation against presumed energy requirements. Eur J Clin Nutr $\mathbf{5 1}$, 405-413.

13. Lof M \& Forsum E (2004) Validation of energy intake by dietary recall against different methods to assess energy expenditure. J Hum Nutr Diet 17, 471-480.

14. Rasmussen LB, Matthiessen J, Biltoft-Jensen A \& Tetens I (2007) Characteristics of misreporters of dietary intake and physical activity. Public Health Nutr 10, 230-237.

15. Sallis JF \& Saelens BE (2000) Assessment of physical activity by self-report: status, limitations, and future directions. Res $Q$ Exerc Sports 71, 1-4.

16. Adams SA, Matthews CE, Ebbeling CB, Moore CG, Cunningham JE, Fulton J \& Hebert JR (2005) The effect of social desirability and social approval on self-reports of physical activity. Am J Epidemiol 161, 389-398.

17. Racette SB, Schoeller DA \& Lushner RF (1995) Comparison of health rate and physical activity recall with doubly labeled water in obese women. Med Sci Sports Exerc 27, 126-133.

18. National Cancer Institute (2007) What is the OPEN study? http://riskfactor.cancer.gov/studies/open/ (accessed May 2007).

19. Berhane Y, Wall S, Kebede D et al. (1999) The Butajira Rural Health Program 1987-1999. Ethiop J Health Development 13, 36-44.

20. Schofield WN (1985) Predicting basal metabolic rate, new standards and review of previous work. Hum Nutr Clin Nutr 39, 5-41.

21. The Ethiopian Health and Nutrition Research Institute (1995) Food Composition Tables for Ethiopia. Part I-IV. Addis Ababa: EHNRI.

22. Ainsworth BE, Haskell WL, Leon AS, Jacobs DR Jr, Montoye HJ, Sallis JF \& Paffenbarger RS Jr (1993) Compendium of physical activities: classification of energy costs of human physical activities. Med Sci Sports Exerc 25, 71-80.

23. Ainsworth BE, Haskell WL, Whitt MC et al. (2000) Compendium of physical activities: an update of activity codes and MET intensities. Med Sci Sports Exerc 32, S498-S504.

24. Goldberg GR, Black AE, Jebb SA, Cole TJ, Murgatroyd PR, Coward WA \& Prentice AM (1991) Critical evaluation of energy intake data using fundamental principles of energy physiology. 1. Derivation of cut-off limits to identify underrecording. Eur J Clin Nutr 45, 569-581.

25. Food and Agriculture Organization of the United Nations/ World Health Organization/United Nations University (2004) Human Energy Requirements. Report of a Joint FAO/WHO/UNU Expert Consultation. FAO Food and Nutrition Technical Report Series no. 1, pp. 92-96. Geneva: $\mathrm{FAO} / \mathrm{WHO} / \mathrm{UNU}$.

26. Black AE (2000) The sensitivity and specificity of the Goldberg cutoff for EI:BMR for identifying diet reports of poor validity. Eur J Clin Nutr 54, 395-404.

27. Black AE (2000) Critical evaluation of energy intake using the Goldberg cut-off for energy intake:basal metabolic rate. A practical guide to its calculation, use and limitations. Int $J$ Obes Relat Metab Disord 24, 1119-1130. 
28. Bingham S (1987) The dietary assessment of individuals: methods, accuracy, new techniques and recommendations. Nutr Abstr Rev 57, 705-742.

29. Nelson M, Black AE, Morris JA \& Cole TJ (1989) Betweenand within-subject variation in nutrient intake from infancy to old age: estimating the number of days required to rank dietary intake with required precision. Am J Clin Nutr $\mathbf{5 0}$ 156-167.

30. Black AE \& Cole TJ (2000) Within- and between-subject variation in energy expenditure measured by the doublylabeled water technique: implications for validating reported dietary energy intake. Eur J Clin Nutr 54, 386-394.

31. Bland JM \& Altman DG (1986) Statistical method for assessing agreement between two methods of clinical measurement. Lancet 1, 307-310.

32. Federal Democratic Republic of Ethiopia, Central Statistical Authority (2001) Report on the 1999/2000 Household Income, Consumption and Expenditure Survey. Statistical Bulletin, vol. 258. Addis Ababa: FDRE/CSA

33. Livingstone MBE \& Black AE (2003) Markers of the validity of reported energy intake. J Nutr 133, 895S-920S.

34. Black AE (1999) Small eaters or under-reporters? In Progress in Obesity Research, pp. 223-228 [G Ailhaud and
B Guy-Grand, editors]. Paris: John Libbey/8th International Congress on Obesity.

35. Black AE, Welch AA \& Bingham SA (2000) Validation of dietary intakes measured by diet history against $24 \mathrm{~h}$ urinary nitrogen excretion and energy expenditure measured by the doubly-labelled water method in middle-aged women. Br J Nutr 83, 341-354.

36. Black AE, Jebb SA, Bingham SA, Runswich SA \& Poppitt SD (1995) The validation of energy and protein intakes by doubly labeled water and 24-hour urinary nitrogen excretion in post-obese subjects. J Hum Nutr Diet 8, 51-64.

37. Mendez MA, Wynter S, Wilks R \& Forrester T (2004) Underand overreporying of energy is related to obesity, lifestyle factors and food group intakes in Jamaican adults. Public Health Nutr 7, 9-19.

38. MacIntyre UE, Venter CS \& Vorster HH (2001) A culturesensitive quantitative food frequency questionnaire used in an African population: 2. Relative validation by 7-day weighed records and biomarkers. Public Health Nutr $\mathbf{4}$, 63-71.

39. Ainsworth BE (2002) The Compendium of Physical Activities Tracking Guide. http://prevention.sph.sc.edu/ tools/docs/documents_compendium.pdf (accessed May 2007). 